\title{
Kenevir (Cannabis sativa L.) saplarından kağıt hamuru ve kağıt üretiminin araştırılması
}

\author{
Ahmet Tutuşa (iD, Mustafa Çiçeklera,* (D), Bekir Yemşen $^{b}$ (D), Sibel Bilgiç Karab (D), Tamer Sözbirb (iD)
}

\begin{abstract}
Özet: Bu çalışmada, soymuk lifleri alınmış kenevir (Cannabis sativa L.) saplarının kağıt hamuru ve kağıt üretiminde kullanımı ve üretilen kağıtların bazı mekanik ve optik özellikleri araştııılmıştır. Soymuk liflerinden arındırılmış kenevir saplarının kimyasal bileşenleri ve lif morfolojik özellikleri belirlenerek kağıt hamuru ve kağıt üretimine uygunluğu tespit edilmiştir. Kenevir saplarının holoselüloz, selüloz ve lignin içerikleri sırasıyla $\% 79.7, \% 52.0 \mathrm{ve} \% 22.2$, lif uzunluğu, lif genişliği ve lümen çapı ise sırasıyla 0.60 $\mathrm{mm}, 28.8 \mu \mathrm{m}$ ve $13.4 \mu \mathrm{m}$ bulunmuştur. Bu veriler doğrultusunda, kenevir saplarından Kraft yöntemi ile pişirme yapılarak kağıt hamuru üretimi gerçekleştirilmiştir. Kenevir saplarından elde edilen kağıt hamurunun verimi, kappa numarası ve viskozite değerleri sırasıyla \%48.2, 39 ve $1400 \mathrm{~cm}^{3} / \mathrm{gr}$ olarak tespit edilmiștir. Bu hamurlardan üretilen kağıtların kopma uzunluğu ve parlaklık değerleri ise sırasıyla $6.87 \mathrm{~km}$ ve 33.34 \%ISO olarak ölçülmüştür. Sonuç olarak, soymuk liflerinden arındırılmış kenevir saplarından yüksek verimde ve mukavemette kağıt hamuru üretimi gerçekleştirilebilmektedir. Aynı zamanda, kağıt hamurları düşük kappa numarasına ve yüksek viskozite değerine sahip olduğundan ağartılması kolay olmaktadır.

Anahtar kelimeler: Kenevir sapı, Kağıt hamuru, Kağıt, Kağıt özellikleri
\end{abstract}

\section{Investigation of pulp and paper production from hemp (Cannabis sativa L.) stalks}

\begin{abstract}
In this study, the use of bast fibers removed hemp (Cannabis sativa L.) stalks in pulp and paper production and some physical and optical properties of the produced papers were investigated. The chemical components and fiber morphological properties of hemp stalks free of bast fibers were determined and their suitability for pulp and paper production was examined. The holocellulose, cellulose and lignin contents of the hemp stalks were $79.7 \%, 52.0 \%$ and $22.2 \%$, respectively, while fiber length, fiber width and lumen diameter were $0.60 \mathrm{~mm}, 28.8 \mu \mathrm{m}$ and $13.4 \mu \mathrm{m}$, respectively. In line with these data, pulp production was carried out by cooking the hemp stalks with the Kraft cooking method. The yield, kappa number and viscosity values of pulp obtained from hemp stalks were determined as $48.2 \%, 39$ and $1400 \mathrm{~cm}^{3} / \mathrm{g}$, respectively. The breaking length and brightness values of the papers produced from these pulps were measured as $6.87 \mathrm{~km}$ and $33.34 \%$ ISO, respectively. Consequently, high yield and strength pulps can be produced from hemp stalks free of bast fibers, and since it has a low kappa number and high viscosity, it can be easily bleached.
\end{abstract}

Keywords: Hemp stalk, Pulp, Paper, Paper properties

\section{Giriş}

Kenevir (Cannabis sativa L.), Cannabaceae familyasina ait, tek y1llı bitki cinsidir. Bilinen ilk bitkisel lif kaynaklarından biri olup, saplarında bulunan soymuk lifleri iplik, dokuma, kumaş ve kağıt üretiminde, sapları ise lif levha, yonga levha, kağıt hamuru ve kağıt üretiminde kullanılmaktadır (ElSohly ve Gul, 2014). Lif bitkileri arasında önemli bir konuma sahip olan kenevir bitkisine olan ilgi II. Dünya savaşından sonra belirli ölçüde azalmıştır. Bunun başlica nedenlerinden biri sentetik liflerin daha kolay ve ekonomik olarak üretilmesi, kenevir bitkisinden üretilen ürünlerin önüne geçmesidir. Bunların yanı sıra, kenevirden esrar üretilmesi de ekim alanlarının sınırlandırılması ve sisal, abaka ve jüt liflerinin kenevir liflerinin alternatifi olması da bu bitkiye olan ilgiyi azaltmıştır (Aytaç vd., 2017).

Kenevir kağıt üretiminde oduna alternatif hammadde olarak önerilmektedir. Yaklaşı 1-5 m boya ve 1-6 cm çapa ulaşan düz, dalsız ve oyuklu bir gövdeye sahip olan kenevir 4-5 ayda gelișimini tamamlamaktadır (Shmulsky ve Jones, 2011). Ülkemizde farklı iklim koşullarına sahip bazı bölgelerde kenevir tarımı yapılmaktadır. 2016 yılında resmi gazetede yayınlanan "Kenevir Ekimi ve Kontrolü Hakkında Yönetmelik" uyarınca ülkemizde 19 ilde kenevir tarımı yapilabilmektedir (GTHB, 2018).

Türkiye'de 2019 yılında toplam kağıt tüketim miktarı yaklaşık 8 milyon ton'a ulaşarak \%5.5 büyümüştür. Ancak, sektörün yurt içi üretimini 5.5 milyon ton'a ulaştırarak büyüme oranını \%8.3'e yükselttiği görülmektedir (Faostat, 2021). Ülkemizde kağıt-karton sektörü gelişme potansiyeli çok yüksek bir sektör olup, sağlam ve kalıcı gelişimi ile rekabet edebilir güçlü yapısını oluşturmak için, yetersiz olan hammadde sorununun çözümünde uzun vadeli devlet politikası gerekmektedir. Orman ve tarım alanlarında endüstriyel ağaçlandırma ve lif kaynaklarının üretimi ile ilgili yeni işletim politikaları, katı atık yönetmeliklerinin

\footnotetext{
a a Kahramanmaraş Sütçü İmam Üniversitesi, Orman Fakültesi, Orman Endüstri Müh. Bölümü, 46050, Onikișubat-Kahramanmaraș

b Kahramanmaraş Kağıt Sanayi ve Ticaret A.Ş. 46090, DulkadiroğluKahramanmaraş

@ * Corresponding author (İletişim yazarı): mcicekler87@gmail.com

$\checkmark \quad$ Received (Geliş tarihi): 30.06.2021, Accepted (Kabul tarihi): 31.08 .2021
}

Citation (Atıf): Tutuş, A., Çiçekler, M., Yemşen, B., Bilgiç Kara, S., Sözbir, T., 2021. Kenevir (Cannabis sativa L.) saplarından kağıt hamuru ve kağıt üretiminin araştırılması. Turkish Journal of Forestry, 22(3): 311-317. DOI: $10.18182 / \mathrm{tjf} .958584$ 
belediyelerce uygulama etkinliği, atık kağıtların ihracatının engellenmesi, enerji fiyatlarında indirim teşvikleri uygulanması, gümrüklerin bilinçli olarak kontrol altına alınması, haksız rekabet gibi konular kağıt ve karton sektörünün önemli öncelikleridir.

Ülkemizde çoğunlukla atık kağıtlar oluklu mukavva (ambalaj) kağıtlarının üretiminde değerlendirilmektedir. Ancak, atık kağıtlar kalitesi ve özelliklerine göre en fazla 56 kez geri dönüştürülebilmektedir. Geri dönüşüm sırasında meydana gelen hornifikasyon olarak da adlandırılan liflerin bağ yapma kabiliyeti ve yüzey alanları azalmaktadır (Şahin, 2014). Dolayısıyla üretilen kağıtların direnç özellikleri düşmekte ve geri dönüşüm sayısı arttıkça istenilen özellikleri elde etmek zorlaşmaktadır (Çiçekler, 2019). Bu nedenle, oluklu mukavva kağıdı üretiminde direnç arttırıcı kimyasallar kullanılmakta olup hem üretim maliyetleri hem de çevresel sorunlar artmaktadır. Ülkemizde birincil lif üretimi y1llık 70 bin ton olup bu miktar kağıt üreticileri için oldukça azdır. Kenevir saplarının birincil lif üretiminde değerlendirilerek yıllık üretim kapasitesinin arttırılması kağıt üreticilerin taleplerinin karşılanmasında ve ekonominin geliştirilmesinde önemli bir yer tutacaktır. Zira her bir geri dönüşüm esnasında kağıt liflerinde deformasyonlar meydana geldiğinden ve kırıntı lif oranı arttığından dolayı gün geçtikçe istenilen direnç özellikleri sağlanamayacak ve birincil life ihtiyaç duyulacaktır.

Türkiye'de kağıt ve karton ürünleri üretiminde hammadde ve girdi tedarikinde rakipleri ile karşılaştırıldığında sınırlı olanaklara sahiptir ve ağartılmış ve ağartılmamış selüloz temininde önemli ölçüde dışa bağımlıdır. Kenevir bitkisinin soymuk lifleri genel olarak kağıt hamuru üretiminde değerlendirilirken bu çalışmada soymuk lifleri alınmış kenevir saplarından sülfat (kraft) pişirme yöntemi ile yüksek verimli ve sağlam kağıt hamuru üretimi olanakları araştırılmıştır.

\section{Materyal ve yöntem}

\subsection{Materyal}

Çalışmada kullanılan soymuk lifleri alınmış kenevir sapları (Şekil 1) Samsun ilinin Vezirköprü ilçesinden temin edilmiştir. Saplar önce ikiye yarılıp 4-6 cm uzunluğunda kesilerek yongalanmış ve kağıt hamuru üretiminde kullanılmıştır.

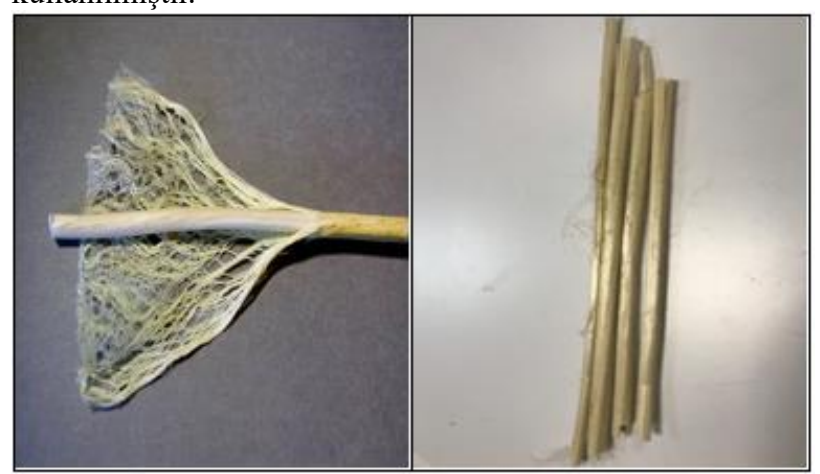

Şekil 1. Soymuk lifleri alınmış kenevir sapları

\subsection{Kenevir saplarının kimyasal bileşenlerinin ve lif morfolojik özelliklerinin belirlenmesi}

Bir hammaddenin kağıt hamuru ve kağıt üretimine uygunluğunu belirlemede yapılacak işlemler arasında ilk sırayı genel olarak hammaddenin kimyasal içeriğinin ve lif morfolojik özelliklerinin belirlenmesi almaktadır. $\mathrm{Bu}$ işlemler hammaddeden elde edilecek kağıt hamurunun ve kağıtların bazı özelliklerinin tahmin edilmesinde kolaylık sağlamaktadır. Selüloz oranı genel olarak verim, lignin oranı pişirme koşulları ve hemiselüloz oranı ve çeşidi ise hamurun sağlamlığ ve dövülme özellikleri üzerine etkilidir (Eroğlu, 1980).

$\mathrm{Bu}$ nedenle, kağıt hamuru üretiminde kullanılan kenevir sapları kirliliklerinden arındırılarak küçük parçalara getirilmiş ve TAPPI T257 (2012) standardına göre bir değirmende ögütülerek 40 mesh $(425 \mu)$ ve 60 mesh $(250 \mu)$ 'lik eleklerden elenmiş ve 60 mesh elek üzerinde kalan örnekler rutubetleri belirlenerek kimyasal analizlerde kullanılmak üzere depolanmıştır.

Daha sonra örnekler aşağıda belirtilen kimyasal analizler ilgili standartlara bağlı kalınarak yapılmıştır.

Holoselüloz oranı: Wise'nin klorit metodu (Wise ve Karl, 1962).

Selüloz oranı: Kürschner-Hoffer metodu (Kürschner ve Hoffer, 1969).

Lignin oran1: TAPPI T222 (2006).

Alfa selüloz oranı: TAPPI T203 (2009).

Kül oranı: TAPPI T211 (2007).

Toluen- Etanol çözünürlük oranı: ASTM D1107 (2007).

Suda çözünürlük oranı: TAPPI T207 (2008).

\% 1'lik NaOH'de çözünürlük oranı: TAPPI T212 (2018)

Kenevir saplarının lif morfolojik özelliklerinden lif uzunluğunu, lif genişliğini, çeper kalınlığını ve lümen çapını belirlemek için örneklere klorit maserasyon metodu uygulanmış ve lifler bireysel hale getirilmiştir. Masere edilen liflerden preperatlar hazırlanmış ve Nikon FS1 foto mikroskobunda ölçümler yapılmıştır.

Hammaddelerin kağıt hamuru ve kağıt üretimine uygunluğunda sadece selülozun kimyasal özellikleri veya kolay elde edilişi değil bunun yanı sıra lif morfolojik özellikleri ve bu özellikler kullanılarak hesaplanan lif parametreleri de önemlidir. Kağıt özelliklerini etkileyen lif boyutları ile bu boyutlar arasındaki ilişkilerin irdelenmesinde aşağıdaki parametreler kullanılmaktadır (Bozkurt, 1971; Göksel, 1986; Tank vd., 1990; Yaman ve Gencer, 2005).

Keçeleşme Oranı: Lif Uzunluğu / Lif Genişliğii, Elastiklik Katsayısı: Lümen Genişliği x 100 / Lif Genişliği, Rijidite Katsayısı: Lif Çeper Kalınlığı x 100 / Lif Genişliği, Mühlstep Oranı: Lif Çeper Alanı x 100 / Lif Enine Kesit Alanı, Runkel Oranı: 2 x Lif Çeper Kalınlığı / Lümen Genişliği, "F" Faktörü: Lif Uzunluğu / Lif Çeper Kalınlığı

\subsection{Kenevir saplarından kağıt hamuru üretimi}

Kenevir saplarının pişirme işleminde elektrik ile ssıtılan, yüksek basınca ( 25 bar) dayanıklı, dakikada yaklaşık 4 tam tur dönebilen, otomatik kontrol panosu ile sicaklığı kontrol edilebilen 15 lt kapasiteye sahip kesintili üretim yapan pişirme kazanı kullanılmıştır. Pişirme işleminde 500 gr tam kuru kenevir sapı kullanılmış ve doldurma işlemleri el ile yapılmıştır. Pişirme işleminde sıcaklık termometre vasıtasıyla kontrol edilerek $\pm 2-5{ }^{\circ} \mathrm{C}$ hassasiyetle çalışılmıştır. 
Kenevir saplarına uygulanan pişirme koşulu aşağıda Çizelge 1 'de verilmiştir.

Pişirme işlemi bittikten sonra kazan boşaltılmış ve 200 mesh'lik elek üzerine aktarılarak hamur içerisinde bulunan ve lignin içeren siyah çözelti yıkanarak uzaklaştırılmıştır. Yıkama işleminden sonra kağıt hamurları lif açıcıya aktarılmış ve 10 dakika boyunca liflendirilmiştir. Daha sonra $0.15 \mathrm{~mm}$ yarık açıklığına sahip sarsıntılı elekte elenerek pişmeyen kısımlarından arındırılmıştır. Kağıt hamurlarının viskozite değerinin ve kappa numarasının belirlenmesinde sirasiyla TAPPI T230 (2013) ve TAPPI T236 (2013) standartları kullanılmıştır.

\subsection{Kenevir saplarından kağıt üretimi ve testleri}

Kenevir saplarından elde edilen kağıt hamurları test kağıdı formasyonu öncesinde 10 lt kapasiteli karıştırıcıda belirli kesafette homojen olarak karıştırılmış ve serbestlik dereceleri ISO 5267-1 (1999) metoduna göre Schopper Riegler aleti kullanılarak belirlenmiştir. Kağıt hamurları Hollander cihazında $35 \pm 2 \mathrm{SR}^{\circ}$ derecesinde dövme işlemine tabi tutulmuştur ve Rapid Köthen RK-21 laboratuvar tipi kağıt makinesinde $70\left(\mathrm{~g} / \mathrm{m}^{2}\right)$ gramajında test kağıtları üretilmiştir.

Kağıt hamurlarından elde edilen test kağıtları TAPPI T402 (2013) standardına göre sıcaklığ $23 \pm 1{ }^{\circ} \mathrm{C}$ ve bağıl nemi $\% 50 \pm 2$ olan kondisyon odasinda 24 saat kondisyonlandıktan sonra aşağıdaki standartlara bağlı kalınarak Çizelge 2'de verilen mekanik ve optik testler yapılmıştır.

Çizelge 1. Kenevir (Kendir) saplarına uygulanan kraft pişirme koşulları

\begin{tabular}{lr}
\hline Pişirme koşulları & Değer \\
\hline Aktif alkali oranı (\%) & 22 \\
Sülfidite oranı $(\%)$ & 24 \\
Pişirme sıcaklığı $\left({ }^{\circ} \mathrm{C}\right)$ & 150 \\
Maksimum sıcaklığa çıkış süresi (dakika) & 40 \\
Pişirme süresi (dakika) & 60 \\
Çözelti/yonga oranı & $5 / 1$ \\
Kullanılan hammadde miktarı (gram) & 500 \\
\hline
\end{tabular}

Çizelge 2. Kağıtlara uygulanan mekanik ve optik testler ile kullanılan standartlar

\begin{tabular}{ll}
\hline Mekanik ve optik özellikler & Standartlar \\
\hline Kopma uzunluğ $(\mathrm{km})$ & TAPPI T494 (2006) \\
Patlama indisi $\left(\mathrm{kPa} \mathrm{m}^{2} / \mathrm{g}\right)$ & TAPPI T403 $(2015)$ \\
Yırtılma indisi $\left(\mathrm{mN}^{2} . \mathrm{m}^{2} . \mathrm{g}\right)$ & TAPPI T414 $(2012)$ \\
Parlaklık $(\%$ ISO) & ISO 2470-1 (2016) \\
Sarılık (E313) & ASTM E313 (2010) \\
\hline
\end{tabular}

Her bir pişirmeden 10 adet test kağıdı üretilmiş ve yukarıda belirtilen mekanik ve optik testlere tabi tutulmuştur.

\section{Bulgular ve tartışma}

\subsection{Kenevir saplarının kimyasal bileşenleri ve lif morfolojik özellikleri}

Aşağıda Çizelge 3'te kenevir saplarının ve diğer odun ve yıllık bitki türlerinin kimyasal içerikleri verilmiştir. $\mathrm{Bu}$ çalışmada kenevir sapı için tespit edilen kimyasal analiz sonuçları daha önce yapılmış olan çalışmalar ile karşılaştırıldığında elde edilen sonuçların genel olarak literatürdeki değerlerle uyum gösterdiği belirlenmiştir.

Kenevir saplarının selüloz ve lignin içeriği diğer yıllık bitkiler ile uyum gösterirken holoselüloz içeriği yüksek çıkmıştır. Bunun başlıca nedeni ise içeriğinde bulunan hemiselülozdan kaynaklanmaktadır (Tutuş ve Çiçekler, 2016). Holoselüloz içeriği yapraklı ağaçlara ve iğne yapraklı ağaçlara göre daha yüksektir. Bilindiği üzere holoselüloz, selüloz ve hemiselülozun birleşimi olup, kenevir sapı, yapraklı ağaçlar, buğday sapı ve iğne yapraklı ağaçlara göre yüksek oranda hemiselüloz içermektedir. Yapılan bu çalışmada kenevir sapının holoselüloz, selüloz ve lignin içeriği sırasıyla \%79.67, \%52.03 ve \%22.24 olarak tespit edilmiştir. Ayrıca kül oranının düşük ve ekstraktif maddelerin az olması pişirmeyi kolaylaştırmıştır. Aşağıda Çizelge 4'te kenevir sapları ve bazı diğer türlerin lif morfolojik özellikleri verilmiş̧ir.

Çizelge 3. Kenevir saplarına, bazı yıllık bitkilere ve odunlara ait kimyasal bileşen oranları

\begin{tabular}{|c|c|c|c|c|c|c|c|c|c|c|}
\hline \multirow{2}{*}{$\begin{array}{l}\text { Yıllık bitki ve } \\
\text { odun türleri }\end{array}$} & \multicolumn{9}{|c|}{ Kimyasal bileşenler ve çözünürlükler (\%) } & \multirow[b]{2}{*}{ Kaynaklar } \\
\hline & Holoselüloz & Selüloz & $\begin{array}{c}\text { Alfa } \\
\text { selüloz }\end{array}$ & Lignin & Kül & $\begin{array}{c}\text { Ekstrak } \\
\text { tifler }\end{array}$ & $\begin{array}{l}\text { \%1'lik } \\
\mathrm{NaOH} \\
\end{array}$ & $\begin{array}{c}\text { Sicak } \\
\text { su }\end{array}$ & Soğuk su & \\
\hline Kenevir sap1 & 79.67 & 52.03 & 41.54 & 22.24 & 0.73 & 1.27 & 22.89 & 3.48 & 1.73 & Bu çalışmadaki tespit \\
\hline Buğday sapı & 77.99 & 51.66 & 39.22 & 17.56 & 7.64 & 5.68 & 43.23 & 12.81 & 9.78 & Çiçekler, 2019 \\
\hline Kızılçam & 76.64 & 52.62 & 45.76 & 25.16 & 0.52 & 5.99 & 14.90 & 3.15 & 2.42 & Çiçekler, 2019 \\
\hline Pamuk sapı & 75.60 & 45.48 & 39.82 & 18.24 & 2.52 & 6.05 & 30.90 & 14.25 & 11.65 & Ezici, 2010 \\
\hline Buğday sapı & 77.10 & 52.27 & 39.62 & 18.33 & 7.12 & 5.48 & 40.90 & 12.25 & 7.65 & Tutuş ve Eroğlu, 2003 \\
\hline Çavdar sapı & 74.10 & 51.50 & 44.40 & 15.40 & 3.20 & 9.20 & 39.20 & 13.00 & 10.20 & Usta ve Eroğlu, 1988 \\
\hline Misır sap1 & 64.80 & 45.60 & 35.60 & 17.40 & 7.50 & 9.50 & 47.10 & 14.80 & - & Eroğlu vd., 1992 \\
\hline Sarıçam & 73.67 & 46.85 & - & 28.57 & 0.45 & 6.71 & 16.28 & 3.82 & 3.42 & Tutuș vd., 2010 \\
\hline Kızılçam & 78.64 & 54.24 & 48.56 & 27.60 & 0.48 & 7.65 & 14.49 & 2.19 & 1.14 & Tutuş vd., 2012 \\
\hline Karaçam & 67.46 & - & 44.60 & 25.60 & - & 4.28 & 9.43 & 1.69 & 1.29 & Ataç, 2009 \\
\hline İğne yapraklı & $63-74$ & $55-61$ & - & $25-32$ & $0.2-0.5$ & $1-5.8$ & $8-10$ & $1-5$ & $0.5-4$ & Kurc1, 2003 \\
\hline Yapraklı & $72-82$ & $38-55$ & - & $18-26$ & $0.2-0.7$ & $1-6.2$ & $12-25$ & $1-8$ & $0.2-4$ & Kurc1, 2003 \\
\hline
\end{tabular}


Çizelge 4. Kenevir sapı ve bazı türlerin lif morfolojik özellikleri

\begin{tabular}{|c|c|c|c|c|c|}
\hline $\begin{array}{l}\text { Morfolojik özellikler } \\
\text { Türler }\end{array}$ & Lif boyu (mm) & Lif genişliği $(\mu \mathrm{m})$ & Çeper kalınlığg $1(\mu \mathrm{m})$ & Lümen çap1 $(\mu \mathrm{m})$ & Kaynaklar \\
\hline Kenevir sap1 & 0.60 & 28.80 & 7.72 & 13.4 & Bu çalışmadaki tespit \\
\hline Buğday sapı & 0.89 & 14.54 & 5.27 & 4.00 & Ciçekler, 2019 \\
\hline Karaçam & 3.89 & 46.11 & 6.62 & 33.07 & Îstek vd., 2008 \\
\hline Kızılçam & 3.30 & 38.63 & 8.54 & 21.55 & Çiçekler, 2019 \\
\hline Buğday sap1 & 0.88 & 14.11 & 5.15 & 3.79 & Tutuş ve Çiçekler, 2016 \\
\hline Çavdar sapı & 1.15 & 14.7 & 4.6 & 4.2 & Usta ve Eroğlu, 1988 \\
\hline Pamuk sapı & 0.81 & 24.98 & 4.12 & 16.75 & Tutuş vd., 2010 \\
\hline Kanola sap1 & 1.19 & 13.10 & 2.25 & 8.60 & Tofanica vd., 2011 \\
\hline Kızılçam & 2.85 & 52.05 & 8.21 & 35.63 & Gürboy, 2007 \\
\hline Karaçam & 1.21 & 36.12 & 4.95 & 26.23 & Akgül ve Tozluoğlu, 2009 \\
\hline İğne yapraklı A. & $2.7-4.6$ & $32-43$ & - & - & Atchison, 1987 \\
\hline Yapraklı Ağaç & $0.7-1.6$ & $20-40$ & - & - & Atchison, 1987 \\
\hline
\end{tabular}

Kağıt hamuru ve kağıt özelliklerinde kimyasal içerik kadar kullanılan hammaddenin lif morfolojik özellikleri de oldukça etkilidir (Bozkurt ve Erdin, 1989; Serin vd., 2017). Çizelge 4 incelendiğinde, kenevir sapının lif morfolojik özellikleri (Şekil 2) genel olarak literatür ile uyum gösterirken yapraklı ağaç lif morfolojik özellikleri ile benzer özelliktedirler.

Kağıt üretiminde kullanılacak olan hammaddenin lif özellikleri üretilecek kağıtların bazı mekanik özelliklerini etkilemektedir. Metot kısmında bahsedilen lif parametreleri hammaddeden üretilen kağıdın özellikleri hakkında ön bilgiler vermektedir.

Aşağıda Çizelge 5'te kenevir sap1, diğer yıllık bitkiler ve odunların lif morfolojik özelliklerinden yararlanılarak hammaddeden üretilen kağıtların özellikleri hakkında ön bilgi edinmek için bazı parametreler verilmiştir.
Keçeleşme oranı, hammaddenin kağıt üretimine uygunluğunu tespit etmede kullanilan önemli parametrelerden biridir. Bu oran kağıdın kopma, patlama ve yırtılma mukavemetleri gibi mekanik özellikleri açısından önem arz etmektedir. Genellikle iğne yapraklı ağaçlarda bu oranın 70-90, yapraklı ağaçlarda ise 40-60 olması arzu edilir (Tutuş ve Çiçekler, 2016). Bu çalışmada kullanılan kenevir sapının odununun keçeleşme oranı 21.43 olarak bulunmuş olup keçeleşme oranı açısından istenilen değerlerin altındadır. Yapılan diğer çalışmalarda kızılçam keçeleşme oranları 89-98 (Göksel, 1984) ve 77 (Bozkurt vd., 1993) olarak tespit etmişlerdir. Lif morfolojik özelliklerin yetişme koşullarındaki farklılıklara göre değişiklikler gösterebileceği unutulmamalıdır.
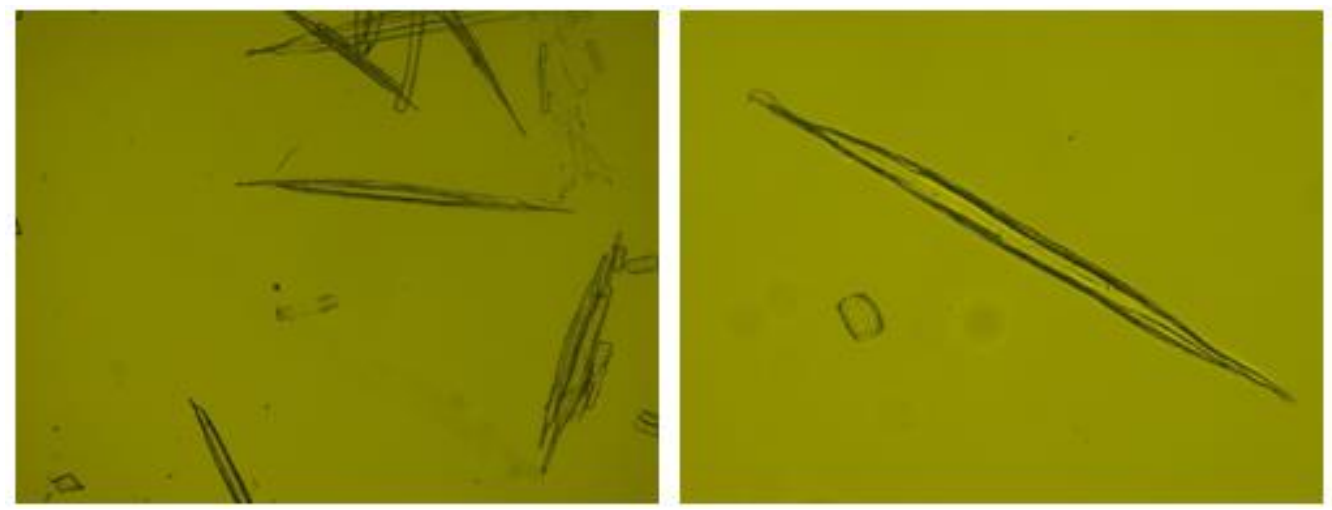

Şekil 2. Kenevir sapı lif görüntüleri

Çizelge 5. Kenevir sapı, bazı yıllık bitki ve odunlara ait kağıt üretimine uygunluk parametreleri

\begin{tabular}{|c|c|c|c|c|c|c|c|}
\hline & $\begin{array}{c}\text { Keçeleşme } \\
\text { oranı }\end{array}$ & $\begin{array}{c}\text { Elastiklik } \\
\text { katsayısı }(\%)\end{array}$ & $\begin{array}{c}\text { Rijidite } \\
\text { katsayıs1 (\%) }\end{array}$ & Runkel oranı & $\begin{array}{c}\text { Mühlstep } \\
\text { oranı }\end{array}$ & F oranı & Kaynaklar \\
\hline Kenevir & 21.43 & 45.49 & 27.25 & 1.32 & 78.23 & 80 & Bu çalışmadaki tespit \\
\hline Buğday sapı & 61.21 & 27.51 & 36.24 & 2.64 & 92.43 & 168 & Çiçekler, 2019 \\
\hline Karaçam & 82.63 & 71.26 & 20.33 & 0.41 & 57.49 & 586 & İstek vd., 2008 \\
\hline Kızılçam & 85.51 & 55.78 & 22.10 & 0.79 & 68.87 & 386 & Çiçekler, 2019 \\
\hline Buğday sapı & 62 & 27 & 36 & 2.7 & - & 170 & Tutuş ve Çiçekler, 2016 \\
\hline Tütün sap1 & 38.97 & 69.9 & - & - & - & - & Deqing vd., 2016 \\
\hline Kanola sap1 & 91 & 64 & 18 & 0.58 & 57.69 & 555 & Tofanica vd., 2011 \\
\hline Kızılçam & 98 & 61.70 & 16.97 & 0.55 & 61.90 & 577 & Bektaş vd., 1999 \\
\hline Sahil çamı & 54.9 & 67.5 & - & 0.5 & - & - & Gülsoy ve Tüfek, 2013 \\
\hline İğne yapraklı a. & $95-120$ & 75 & - & 0.35 & - & - & Smook, 1992 \\
\hline Yapraklı ağaç & $55-75$ & $55-70$ & - & $0.4-0.7$ & - & - & Smook, 1992 \\
\hline
\end{tabular}


Elastiklik katsayısı, lümen çapı ile lif genişliğinin oranlanması ile hesaplanan bir değer olup çekme direnci ile doğru orantılı bir ilişkisi vardır. Bu oranın artması ile kağıtların çekme (kopma) direnci de artmaktadır. Bu oran genel olarak 4 grupta sinıflandırılmaktadır (Kırc1, 2003);

I. Grup: 75 ve üstü (çok esnek lifler), II. Grup: 50-75 (esnek lifler), III. Grup: 30-50 (rijit lifler),

IV. Grup: 30 ve altı (çok rijit lifler)

$\mathrm{Bu}$ değer kenevir saplarında 45.49 olarak bulunmuştur. $\mathrm{Bu}$ değerler doğrultusunda kenevir sapları III. grupta (rijit lifler) yer almaktadır. ,

Rijidite katsayısı, kağıdın mekanik özellikleri üzerine etkili olup bu değer arttıkça mekanik özellikler olumsuz etkilenmektedir (Bostanc1, 1987; Tofanica vd., 2011). Bu çalışmada kullanılan hammadde kenevir sapı yongalarının rijidite katsayısı değeri 27.25 olarak tespit edilmiştir. Literatür ile kıyaslandığında buğday sapları genel olarak 3040, kızılçam odunu lifleri ise 15-25 rijitide katsayısına sahiptir (Bektaş vd., 1999; Tutuş ve Çiçekler, 2016).

Düşük runkel oranı (1'den küçük) olan lifler esnek lifler olup kağıt üretimi esnasında enine kesitlerinin ezilmesi kolay olup lif-lif bağı oluşumu için geniş yüzeye sahip olurlar. 1 'den büyük olan lifler ise rijit kabul edilir ve lifler arası bağlanma sayısı düşük olup kağıtçılıkta istenmemektedir. Bu çalışmada kullanılan kenevir saplarının runkel oranı 1.32 olarak bulunmuştur. Bu doğrultuda kenevir sapından üretilen kağıtların direnç özellikleri runkel oranı 1'e yakın olduğu için iyi olduğu söylenilebilir.

Mühlstep oranı ise hücre çeperinin kağıdın mekanik özellikleri üzerine etkisinin belirlenmesinde kullanılmaktadır. İnce çeperli lifler kağıt yapımında kolayca ezilerek, kağıdın hem yoğunluğunu, hem de direnç özelliklerini olumlu yönde etkiler (Casey, 1961). Kenevir saplarının liflerinde bu oran 78.23 olarak bulunmuştur.

Mühlstep oranına göre lifler 3 grupta sınıflandırılmıştır (Simionescu vd., 1964); 1. Grup 0-30: kurdela şekilli lifler, 2. Grup 31-80: ara formlara sahip silindirik lifler, 3. Grup 81'den büyük: çubuk şekilli lifler. Birinci grupta yer alan lifler kağıt üretimine en uygun lifleri ifade ederken 3 . gruptakiler en az uygun olanları işaret etmektedir (Tofanica vd., 2011). Bu sınıflandırmaya göre kenevir sapları lifleri ara formlara sahip silindirik lifler arasında yer almaktadır.

Lif uzunluğunun çeper kalınlığına oranlanması ile bulunan $\mathrm{F}$ faktörü (Fleksibilite) oranının yüksekliği, bu tür liflerden elde edilecek kağıtların esnekliklerinin iyi olacağını belirler. Daha önce yapılan çalışmalarda, F faktörü kızılçam ve bazı ağaç türleri için şu şekilde bulunmuştur. Kızılçam 606.66, Toros Sediri 410.34, Sahilçamı ilkbahar odunu radyal 745.4, ilkbahar odunu teğet 695.81, Yaz odunu radyal 603.9, Yaz odunu teğet 493.2 (As, 1992). Bu çalışmada kullanılan kenevir sapına ait $\mathrm{F}$ faktörü değeri ise 80 olarak bulunmuştur.

Aşağıda Çizelge 6'da kenevir saplarından Kraft yöntemi ile üretilen kağıt hamurlarının verim, kimyasal, mekanik ve optik özellikleri verilmiştir.

Çizelge 6 incelendiğinde, kenevir saplarından Kraft yöntem ile kağıt hamuru üretildiğinde toplam verim \%48.24 olup kızılçam Kraft hamur verimi ile benzerlik göstermektedir. Yine selüloz zincirinin polimerizasyon derecesini ile ilişkili olan viskozite değerleri de kızılçam hamurları ile benzer çıkmıştır. Hamurun ağartılabilirliğini ve içerdiği lignin oranını tahmin etmede kullanılan kappa numarası kenevir saplarından üretilen hamurlarda 39 , kızılçam ve buğday sapı hamurlarında is sırasıyla 32 ve 37 olarak bulunmuştur. Kenevir sapı hamurlarının viskozite değerleri buğday sapı hamurlarından daha yüksek olup kızılçam hamurları ile benzer özellik göstermektedir. Viskozite değerleri selüloz zinciri uzunluğunun bir göstergesi olup yüksek olması kağıtların daha mukavemetli olmasını göstermektedir. Aynı zamanda, ağartma işlemlerinde kullanılan kimyasalların selülozu degrade ettiği düşünülürse kenevir sapı hamurunun viskozite değerinin yüksek olması mukavemet kayıplarını tolere edebilmektedir.

Kenevir sapları kısa lifli olmasına rağmen mekanik özellikleri oldukça yüksek çıkmıştır. Uzun lifli kızılçam hamurlarından üretilen kağıtlar ile karşılaştırıldığında kopma uzunluğu \%44.5, patlama indisi \%7.04 oranlarında daha yüksek, yırtılma indisi ise $\% 25.8$ oranında daha düşük çıkmıştır. Kopma mukavemeti üzerinde en etki parametrelerden biri lif-lif bağ sayısı ve bu bağların özelliğidir (Casey, 1960). Lif uzunluğunun kağıtların kopma mukavemeti üzerinde kayda değer bir etkisinin olduğu düşünülmektedir. Ancak bazı araştırmacılar lif boyutlarındaki değişimlerinin kopma mukavemeti üzerinde fazla bir etkisinin olmadığına inanmaktadır. Sadece lif uzunluğu değil aynı zamanda lif genişliği de kopma mukavemeti üzerinde etkili olmaktadır. Lif uzunluğu ve genişliği az olan kağıtların kopma mukavemetleri yüksek çıkmaktadır (Eroğlu, 2003). Kenevir saplarından elde edilen kağıtların kopma uzunlukları kısa lifli olmalarına rağmen kızılçam hamurlarından daha yüksek çıkmıştır. Yukarıda belirtildiği gibi kopma mukavemeti üzerine sadece lif uzunlukları değil lif genişlikleri ve lif-lif bağ sayısı ve nitelikleri de etkilidir. Kızılçam hamurlarının lif uzunlukları kenevir saplarından yüksek olduğu için lifleri gerilme ve harcanan enerjiyi daha geniş alana yaymakta bu nedenle yırtılma indisi yüksek çıkmaktadır. Patlama mukavemetini etkileyen faktörlerden en önemlileri lif uzunluğu ve iç bağlanma kabiliyetidir (Clark, 1978; Eroğlu, 2003). Kısa lifli kenevir sapı hamurlarının patlama mukavemeti uzun lifli kızılçam hamurlarından daha yüksek çıkmıştır. Patlama indisi değerleri arasındaki bu farkın kenevir sap1 hamurlarında iç bağlanmanın daha iyi olmasından kaynaklandığı düşünülmektedir.

Kenevir sapı hamurlarının parlaklık değerleri kızılçam hamurlarından \%18.1 ve buğday sapı hamurlarından \%5.27 oranında daha yüksek çıkmıştır. Dolayısıyla, kenevir saplarından üretilen kağıtların ağartılması daha kolay ve ekonomik olacaktır. Aynı zamanda beyaz kağıt üretiminde değerlendirilmesi için gerekli olan ağartma kademelerinde mekanik özelliklerinin yüksek olmasından dolayı herhangi bir güçlük yaşanmayacaktır.

Çizelge 6. Kenevir saplarından kraft yöntemi ile elde edilen kağıtların verim, kimyasal, mekanik ve optik özelliklerine ait bulgular

\begin{tabular}{|c|c|c|c|c|c|c|c|c|}
\hline & $\begin{array}{c}\text { Toplam } \\
\text { verim }(\%)\end{array}$ & $\begin{array}{l}\text { Viskozite } \\
\left(\mathrm{cm}^{3} / \mathrm{gr}\right)\end{array}$ & $\begin{array}{c}\text { Kappa } \\
\text { numarası }\end{array}$ & $\begin{array}{l}\text { Kopma uz. } \\
(\mathrm{km})\end{array}$ & $\begin{array}{c}\text { Patlama İnd. } \\
\left(\mathrm{kPa} \cdot \mathrm{m}^{2} / \mathrm{g}\right)\end{array}$ & $\begin{array}{l}\text { Yirtilma İnd. } \\
\left(\mathrm{mNm}^{2} / \mathrm{g}\right)\end{array}$ & $\begin{array}{c}\text { Parlaklık } \\
\text { (\%ISO) }\end{array}$ & $\begin{array}{l}\text { Sar1lik } \\
\text { (E313) }\end{array}$ \\
\hline Kenevir & 48.24 & 1400 & 39 & 11.4 & 5.32 & 4.18 & 30.18 & 31.1 \\
\hline *Kızılçam & 48.09 & 1484 & 32 & 7.89 & 4.97 & 5.63 & 25.55 & 41.9 \\
\hline *Buğday sap1 & 55.42 & 525 & 37 & 6.12 & 4.40 & 3.39 & 28.67 & 48.3 \\
\hline
\end{tabular}




\section{Sonuç ve öneriler}

Ülkemizde, soymuk lifleri alınmış kenevir saplarından kağıt ve lif levha vb. liflerin ve ürünlerin üretimi yapılmamaktadır. Bu çalışmada, soymuk lifleri alınmış kenevir saplarından kağıt hamuru ve kağıt üretimi araştırılmış olup elde edilen veriler doğrultusunda kenevir saplarından kısa liflere sahip olmalarına rağmen yüksek mukavemette kağıtlar ve ağartılması kolay hamurlar üretilebileceği tespit edilmiştir.

Ağartılmış ve ağartılmamış birincil liflerin ithal edilmesi yerine ülkemizde yetiștirilen kenevir saplarından kağıt hamuru ve kağıt üretilmesi hem ülke ekonomisine, hem de dışa bağımlılığın ve cari açığın azalmasına katkı sağlayacaktır. Kenevir saplarından elde edilen hamurların belirli oranlarda $(\% 20,30,40,50,60$ ve 70$)$ uzun ve kisa lifli odun hamurlarına karıştırılarak çeşitli kağıt üretiminde (bask1, yazı tabı, fotokopi, matbaa, gazete, oluklu mukavva, ambalaj ve temizlik kağıtları) kullanılabileceği değerlendirilmektedir. Böylece bu sektörde hammadde açı̆̆ına katkı sağlayacaktır.

\section{Kaynaklar}

Akgül, M., Tozluoğlu, A., 2009. Some chemical and morphological properties of juvenile woods from beech (Fagus orientalis L.) and pine (Pinus nigra A.) plantations. Trends in Applied Sciences Research, 4: 116-125.

As, N., 1992. Pinus pinaster değişik ırklarının fiziksel, mekanik ve teknolojik özellikleri üzerine etkisi. Doktora Tezi, İstanbul Üniversitesi, Fen Bilimleri Enstitüsü, İstanbul.

ASTM D1107, 2007. Standard test method for ethanol-toluene solubility of wood. ASTM, Pennsylvania, USA.

ASTM E313, 2010. Standard practice for calculating yellowness and whiteness indices from instrumentally measured color coordinates. ASTM, Pennsylvania, USA.

Ataç, Y., 2009. Bazı yapraklı ve iğne yapraklı ağaçların öz ve diri odunlarının kağıt özellikleri yönünden incelenmesi. Doktora Tezi, Bartın Üniversitesi, Fen Bilimleri Enstitüsü, Trabzon.

Atchison, J.E., 1987. Data on non-wood plant fibers. In Secondary Fibers and Non-wood Pulping, $3^{\text {rd }}$ ed., TAPPI Press, Atlanta, GA.

Aytaç, S., Arslanoğlu, Ş.F., Ayan, A.K., 2017. Endüstriyel tip kenevir (Cannabis Sativa L.) yetiştiriciliği. Karadeniz'in Lif Bitkileri Çalıştayı, 5-6 Mayıs, Samsun, s. 27-35.

Bektaş, İ., Tutuş, A., Eroğlu, H., 1999. A study of the suitability of calabrian pine (Pinus brutia Ten.) for pulp and paper manufacture. Tr. J. Agric. For, 23(3): 589-597.

Bostanc1, Ş., 1987. Kağıt Hamuru Üretimi ve Ağartma Teknolojisi. KTÜ Orman Fak., Yay.No. 114 / 13, Trabzon.

Bozkurt, Y., 1971. Doğu Ladini (Picea orientalis Link. et Carr.) ile Toros Karaçamın (Pinus nigra var. caramanica (Loud.) Rehd.)'dan birer ağaçta lif morfolojisi üzerine denemeler. İ.Ü. Orman Fak. Derg., Seri A, 21(1): 70-93.

Bozkurt, Y., Erdin, N., 1989. Odunsu lifler ve tanımı. İstanbul Üniversitesi, Orman Fakültesi Dergisi, Seri B, 39(4): 1-16.

Bozkurt, Y., Göker, Y., Erdin, N., As, N., 1993. Datça kızılçamında anatomik ve teknolojik özellikler. Uluslararası Kızılçam Sempozyumu, 18-23 Ekim, Muğla, s. 628-635.

Casey, J.P., 1960. Pulp and Paper. Vol:3, Interscience Publisher Inc., Newyork

Casey, J.P., 1961. Pulp and Paper. Vol:2, Papermaking, Second Print, Intersecience publ., New York.

Clark, J.A., 1978. Pulp Technology. Mille Freeman Publications, Inc., California.
Çiçekler, M., 2019. Birincil ve ikincil lif karışımlarından yazı tabı, oluklu mukavva ve gazete kağıdı üretiminin araștırılması. Doktora Tezi, KSÜ Fen Bilimleri Enstitüsü, Kahramanmaraş.

Deqing, Z., Ya, D., Guanglin, F., Jie, Y., Lanlan, T., Jun, L., 2016. Chemical composition, fiber morphology and biological structure of tobacco stalks. Product Technology, Vol. 49: 80-86.

ElSohly, M., Gul, W., 2014. Constituents of Cannabis sativa. In Handbook of Cannabis, Pertwee, R. G. (Ed.), Oxford University Press, USA.

Eroğlu, H., 1980. $\mathrm{O}_{2}-\mathrm{NaOH}$ yöntemiyle buğday (Triticum aestivum L.) saplarından kağıt hamuru elde etme olanaklarının araştırılması. Doçentlik Tezi, KTÜ, Trabzon.

Eroğlu, H., 2003. Kağıt ve Kağıt Fiziği Ders Notları. Karadeniz Teknik Üniversitesi, Trabzon.

Eroğlu, H., Usta, M., Kırc1, H., 1992. A review of oxygen pulping conditions of some nonwood plants growing in Turkey. Tappi Pulping Conference, $2^{\text {nd }}$ November, Atlanta, USA, pp. 215-222.

Ezici, A.C., 2010. Pamuk saplarından (Gossypium hirsutum L.) kraft-sodyumborhidrür yöntemiyle kağıt hamuru ve kağıt üretim koşullarının belirlenmesi. Doktora Tezi, KSÜ, Fen Bilimleri Enstitüsü, Kahramanmaraș.

Faostat, 2021. Food and Agriculture Organization of the United Nations website, http://www.fao.org/faostat/en/\#data/QC: Accessed: 22.06.2021.

Göksel, E., 1984. Kızılçam lif morfolojisi ve odunundan sülfat sellülozu elde etme olanakları üzerine araştırmalar. İ.Ü. Yayın No: 3204, Orman Fakültesi Yayın No: 364, İstanbul.

Göksel, E., 1986. Pamuk Saplarının Selüloz ve Kağıt Endüstrisinde Kullanım Olanakları Üzerine Arasstırmalar. İ.Ü. Orman Fak. Derg., Seri A, 36(1): 38-54.

GTHB, 2018. Kenevir Ekimi ve Kontrolü Hakkında Yönetmelik. Gıda Tarım ve Hayvancılık Bakanlığı, Ankara.

Gülsoy, S.K., Tüfek, S., 2013. Effect of chip mixing ratio of Pinus pinaster and Populus tremula on kraft pulp and paper properties. Industrial \& Engineering Chemistry Research, 52(6):23042308.

Gürboy, B., 2007. Kuzey Kıbrıs'ta doğal olarak yetișen kızılçam (Pinus brutia ten.)'ın lif morfolojisi. Süleyman Demirel Üniversitesi, Orman Fakültesi Dergisi, A(2): 119-127.

ISO 2470-1, 2016. Paper, board and pulps - Measurement of diffuse blue reflectance factor - Part 1: Indoor daylight conditions (ISO brightness). International Organization for Standardization, Geneva, Switzerland.

ISO 5267-1, 1999. Pulps - Determination of drainability - Part 1: Schopper-Riegler method. International Organization for Standardization, Geneva, Switzerland.

İstek, A., Eroğlu, H., Gülsoy, S.K., 2008. Karaçamın yaşına bağlı olarak lif ve kağıt özelliklerinin değişimi. Kastamonu University Journal of Forestry Faculty, 8(1), 61-66.

Kırc1, H., 2003. Kağıt Hamuru Endüstrisi Ders Notları. KTÜ, Orman Fakültesi Yayınları, Yayın No:63, Trabzon.

Kürschner, K.. Hoffer. A.. 1969. Ein neues Verfahren zur Bestimmung der Zellulose in Hölzern und Zellstoffen. Technologie und Chemie der Papier-u. Zellstoff-Fabrikation. 26: 125-139.

Serin, Z., Ateş, N., Cavunt, A., 2017. Biberiye (Rosmarinus officinalis L.) saplarının kağıt hamuru ve kağıt üretimine uygunluğunun değerlendirilmesi. Türkiye Ormanc1lık Dergisi, 18(2):155-159.

Shmulsky, R., Jones, P.D., 2011. Forest Products and Wood Science an Introduction. A John Wiley \& Sons, Inc., Publication, United Kingdom.

Simionescu, C.I., Grigora, S., Cern atescu-Asandei, A., 1964. Chemistry of wood in R.P.R. Bucharest. Academy of Popular Republic of Romania Publishing House, Romania.

Smook, G.A, 1992. Handbook for Pulp and Paper Technologists. Angus Wilde Publications, Vancouver. 
Şahin, H.T., 2014. Geri kazanılmış sekonder liflerin yeniden kullanılması üzerine bir inceleme. SDÜ Orman Fakültesi Dergisi, 15: 183-188.

Tank, T., Göksel, E., Cengiz, M., Gürboy, B., 1990. Hızlı gelişen bazı iğne yapraklı ağaç türlerinin lif ve kağıt teknolojisi yönünden incelenmesi. İ.Ü. Orman Fak. Derg., Seri A, 40(1): 40-50.

Tappi T203, 2009. Alpha-, beta- and gamma-cellulose in pulp. TAPPI, Atlanta, USA.

Tappi T207, 2008. Water solubility of wood and pulp. TAPPI, Atlanta, USA.

Tappi T211, 2007. Ash in wood, pulp, paper and paperboard. TAPPI, Atlanta, USA.

Tappi T212, 2018. One percent sodium hydroxide solubility of wood and pulp. TAPPI, Atlanta, USA.

Tappi T222, 2006. Acid-insoluble lignin in wood and pulp. TAPPI, Atlanta, USA.

Tappi T230, 2013. Viscosity of pulp (capillary viscometer method). TAPPI, Atlanta, USA.

Tappi T236, 2013. Kappa number of pulp. TAPPI, Atlanta, USA.

Tappi T402, 2013. Standard conditioning and testing atmospheres for paper, board, pulp handsheets, and related products. TAPPI, Atlanta, USA.

Tappi T257, 2012. Sampling and preparing wood for analysis. TAPPI, Atlanta, USA.

Tappi T403, 2015. Bursting strength of paper. TAPPI, Atlanta, USA.

Tappi T414, 2012. Internal tearing resistance of paper (ElmendorfType Method). TAPPI, Atlanta, USA.
Tappi T494, 2006. Tensile properties of paper and paperboard. TAPPI, Atlanta, USA.

Tofanica, B.M., Cappelletto, E., Gavrilescu, D., Mueller, K., 2011. Properties of rapeseed (Brassica napus) stalks fibers. Journal of Natural Fibers, 8: 241-262.

Tutuş A., Çiçekler, M., 2016. Evaluation of common wheat stubbles (Triticum aestivum L.) for pulp and paper production. Drvna Industrija, 67(3):271-279.

Tutuş, A., Ateş, S., Deniz, İ., 2010. Pulp and paper production from spruce wood with kraft and modified kraft methods. African Journal of Biotechnology, 9(11): 1648- 1654.

Tutuş, A., Çiçekler, M., Deniz, İ., 2012. Yanmış kızılçam odunlarının kağıt hamuru ve kağıt üretiminde kullanılması. KSÜ Mühendislik Bilimleri Dergisi, Özel Sayı, s:90-95.

Tutuş, A., Eroğlu, H., 2003. A practical solution to silica problem in straw pulping, APPITA Journal, 56(2): 111-115.

Usta, M., Eroğlu, H. 1988. Soda-Oxygen Pulping of Rye Straw, Nonwood Plant Fiber Pulping. Progress Report, 18. Atlanta, USA.

Wise, E.L., Karl, H.L., 1962. Cellulose and Hemicelluloses in Pulp and Paper Science and Technology. Vol. 1. Pulp. Earl. C.L. (Ed.). McGraw Hill-Book Co., New York.

Yaman, B., Gencer, A., 2005. Trabzon koşullarında yetiştirilen Kiwi (Actinidia deliciosa (A. hev.) C. F. Liang \& A. R. Ferguson)'nin lif morfolojisi. Süleyman Demirel Üniversitesi Orman Fakültesi Dergisi, Seri: A, Sayı: 2: 149-155. 